\title{
A case report: ruptured primary ovarian abscess in pregnancy
}

\author{
Dinesh D. Pratapwar*, Namdev M. Bhure, Sarika P. Zunjare
}

Ankur Super Speciality Women’s Hospital, Nanded, Maharashtra, India

Received: 07 July 2021

Accepted: 31 July 2021

\section{*Correspondence:}

Dinesh D. Pratapwar,

E-mail: drdinu31@rediffmail.com

Copyright: () the author(s), publisher and licensee Medip Academy. This is an open-access article distributed under the terms of the Creative Commons Attribution Non-Commercial License, which permits unrestricted non-commercial use, distribution, and reproduction in any medium, provided the original work is properly cited.

\begin{abstract}
Primary ovarian abscess during pregnancy is a very rare entity. The clinical presentation is very vague and hence can be a diagnostic dilemma. Diagnostic laparoscopy gives a definitive diagnosis and an opportunity to treat the entity in same settings. Herein we discussed a case of a ruptured primary ovarian abscess in pregnancy which was successfully managed by laparoscopy. Ovarian abscess is different from tubo-ovarian abscess. A delay in diagnosis may be associated with risk of maternal death and can be detrimental to the fetus also. Surgical drainage of ovarian abscess and conservative and minimally invasive surgical procedure under antibiotics are recommended during pregnancy.
\end{abstract}

Keywords: Primary ovarian abscess, Laparoscopy, Pregnancy, Conservative surgery

\section{INTRODUCTION}

Adnexal mass in pregnancy is a rare entity and those requiring surgical intervention occur with a frequency ranging from 1 in 81 to 1 in 2500 live births. Adnexal masses during pregnancy should be accurately evaluated to identify those who need immediate surgical intervention and those who can be put on wait and watch strategy. In these conditions USG and MRI are both safe and accurate to distinguish between benign and malignant ovarian masses.

Most common pregnancy associated ovarian masses are functional cysts like corpus luteum of pregnancy or theca-lutein cysts. The corpus luteal cyst can have variety of appearances ranging from a simple cyst to a complex cystic lesion with internal debris and thick walls. The adnexal masses which are suspicious of malignancy, torsion and infective mases need immediate attention and intervention. Treatment options should be discussed individually and both open and laparoscopy can be done depending on type of adnexal mass, gestational age and surgical expertise.

Primary ovarian abscess is a primary infection of ovarian parenchyma and is a rare entity and its occurrence during pregnancy is even rarer.

Here we reported a rare case of 12 weeks pregnancy with ruptured primary ovarian abscess. It was managed successfully by laparoscopic approach.

\section{CASE REPORT}

A patient, 27 years old, third gravida with previous two caesarean sections came with acute abdomen. She was of 12 weeks gestational age and was registered elsewhere. She presented with severe lower abdominal pain in the last 4 hours, dragging type, diffuse in nature, associated with lower back pain. She had an episode of vomiting and loose stools. She didn't show any signs and symptoms of systemic inflammatory response syndrome. She did not have urinary complaints or vaginal discharge. She had no past history suggesting tuberculosis, pelvic inflammatory disease, any pelvic or abdominal surgery, appendicitis, tonsillitis, dental caries etc.

The patient underwent two full term caesarean sections, 8 and 6 years back. She gave a past history of IUCD 
insertion, two years back. After 5 months of insertion she noticed that the IUCD thread was coming outside the vagina. She went to her doctor where it was removed. There was no history of pain, fever, bleeding or discharge after removal.

She conceived spontaneously after the removal of IUCD and was alright till 12 weeks of gestation. She presented with acute and severe lower abdominal pain in an emergency. On per abdomen examination there were no signs of peritoneal irritation. On USG there was grossly enlarged left ovary of $7.4 \times 5.5 \mathrm{~cm}$ with e/o multiple cystic lesions having internal echogenic debris. The largest cyst was of size $5.4 \times 3.8 \mathrm{~cm}$. On color Doppler there was e/o vascularity in ovarian stroma s/o multiple hemorrhagic ovarian cysts? infective. There was also moderate free fluid in peritoneal cavity. She was not having any prior pelvic imaging for the reference.

Her blood investigations showed a drop of $\mathrm{Hb}$ to $7.5 \mathrm{~g} \%$ and TLC was 16000/cumm. she was posted for an emergency diagnostic laparoscopy under general anaesthesia. Intra operatively, there was e/o of pyoperitonium (Figure 1). Around $500 \mathrm{ml}$ of frank foulsmelling pus sucked out. There was also evidence of left ovarian cystic mass adherent to surrounding structures (Figure 2). Upon adhesiolysis it was found that it was an ovarian abscess and pus was coming out in peritoneal cavity through a small hole in the abscess cavity. Left fallopian tube was normal. Right tube and ovary were normal. Adherent ovarian infected mass was separated from the lateral pelvic wall (Figure 3) and left salpingoophorectomy was done (Figure 4). Thorough irrigation and suction was done. Utmost care was taken to leave the gravid uterus undisturbed. Specimen was retrieved through left lower accessory port and sent for histopathological examination which showed it was a luteal cyst with inflammation of its wall.

Post-operatively she was given broad spectrum intravenous antibiotics for 5 days. Her post-operative course was uneventful. She was discharged in a good condition. She followed regularly in antenatal OPD and she was 30 weeks in her last follow-up.

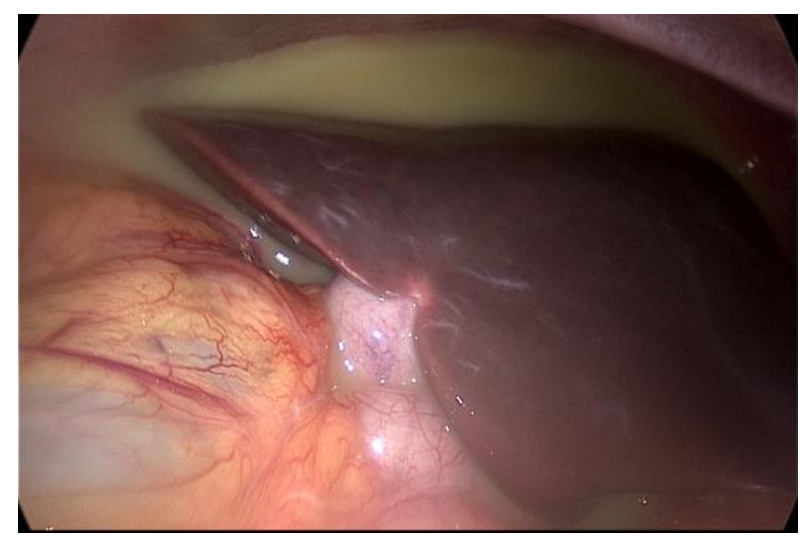

Figure 1: Pyoperitoneum.

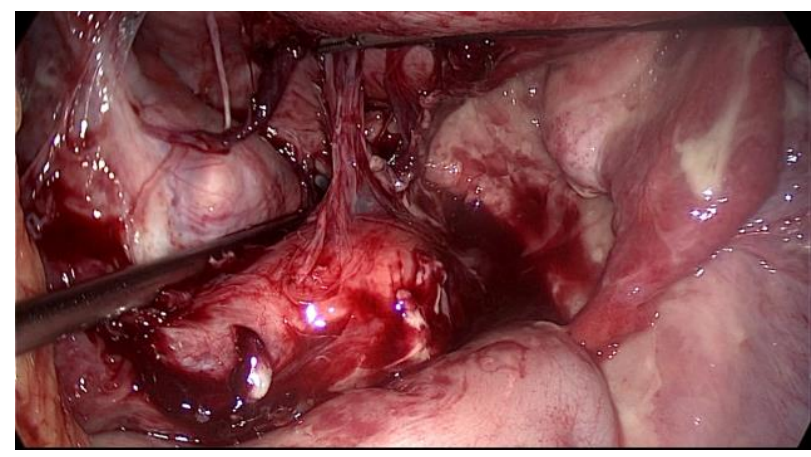

Figure 2: Ruptured left ovarian abscess.

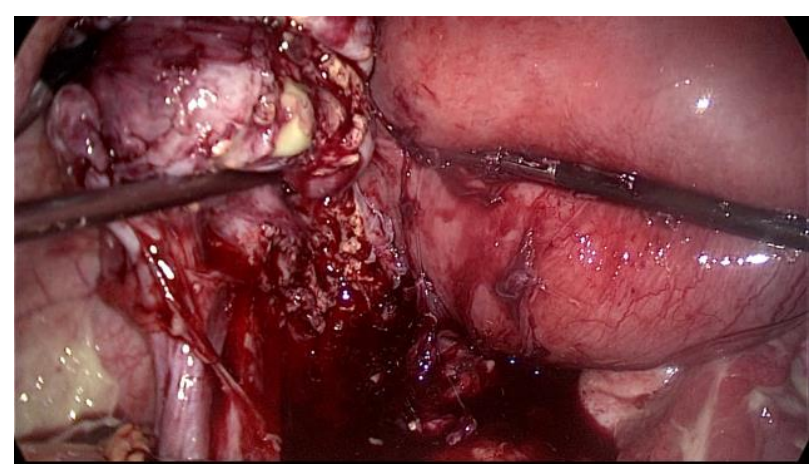

Figure 3: Separation of adherent ovarian infected mass from lateral pelvic wall.

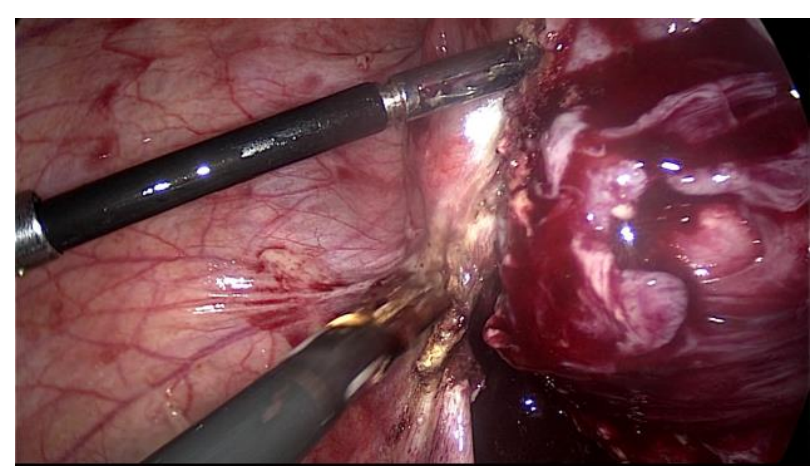

Figure 4: Surgical removal of left adnexa.

\section{DISCUSSION}

In this case it was a primary ovarian abscess as the same sided fallopian tube was normal. Isolated ovarian abscess without salpingitis is a rare entity. Our patient had h/o IUCD insertion which was removed few months prior to conception. A $\mathrm{Cu}-\mathrm{T}$ complication like partial perforation into left uterine wall and hence into left parametrium may explain its low placement and causing ascending infection into left adnexa. In this way this infection saved right adnexa totally but affected left adnexa partially. This explains her conception soon after IUCD removal. Progression during pregnancy can explained due to altered immunity and increased vascularity during pregnancy. It seemed to be a low-grade infection which presented itself because of rupture causing abdominal pain and related 
vagal symptoms.

Etiology of ovarian abscess can be intrauterine devices, secondary to actinomyces, secondary infection in a dermoid cyst, serous cystadenoma or simple ovarian cyst. Ovarian abscess is also a known complication of transvaginal oocyte retrieval, occurring in approximately $0.2-2.2 \%$ of cases. ${ }^{1}$ Ovarian abscess is different from tuboovarian abscess. Tubo-ovarian abscess involves the ovary by secondary spread from the infected fallopian tube whereas ovarian abscess is primarily in the ovary. ${ }^{2}$ Women with ovarian abscess during pregnancy may present with a wide range of clinical symptoms. Diagnosing a ruptured ovarian abscess is easier than unruptured due to features of diffuse peritonitis. An unruptured abscess presents with variable clinical presentation. Most common presenting symptom would be an indolent dull aching abdominal pain. Low-grade fever may be the only presentation in half of the patients. Fetal loss rate has also been reported, most often as spontaneous septic abortions. A delay in diagnosis may be associated with risk of maternal death and can be detrimental to the fetus also. Ruptured tubo-ovarian abscess requires an aggressive and primarily surgical approach to minimize catastrophic sequelae.

Surgical drainage of ovarian abscess and conservative surgical procedure under antibiotics are recommended during pregnancy, albeit there is no consensus on patient management. ${ }^{3}$ Fertility rate following ovarian abscess management may be relatively better when compared with tubo-ovarian abscess as tubal mucosa is spared in primary ovarian abscess. ${ }^{4} \mathrm{~A}$ delay in diagnosis and intervention may be detrimental to both mother and the fetus. Elective surgery is done for any mass greater than $6 \mathrm{~cm}$ in diameter that continues to be seen in the second trimester except uterine leiomyoma. ${ }^{5}$

\section{CONCLUSION}

Thus, ovarian abscess in pregnancy is a rare condition. It increases fetal and maternal morbidity and mortality rate.
Clinically presenting from ruptured to unruptured, it has vague complaints and presentations. Early diagnosis and intervention would yield good results both in mother and fetus. As in this case, with careful clinical evaluation and timely management the fetus and mother are doing well.

\section{ACKNOWLEDGMENTS}

Author would like to acknowledge Dr Arun Mahale Ex prof. Government Medical College Nanded, Maharashtra, India for his support and guidance throughout.

Funding: No funding sources

Conflict of interest: None declared

Ethical approval: Not required

\section{REFERENCES}

1. Akira S, Yamanaka A, Ishihara T, Takeshita T, Araki T. Gasless laparoscopic ovarian cystectomy during pregnancy: comparison with laparotomy. Am J Obstet Gynecol. 1999;180(3):554-7.

2. Wetchler SJ, Dunn LJ. Ovarian abscess. Report of a case and a review of the literature. Obstet Gynecol Surv. 1985;40(7):476-85.

3. Yalcin OT, Tanir HM, Eskalen M. Unruptured pelvic abscesses in pregnancy: report of two cases. Gynecol Obstet Invest. 2002;53(2):133-4.

4. Ginsburg DS, Stern JL, Hamod KA, Genadry R, Spence MR. Tubo-ovarian abscess: a retrospective review. Am J Obstet Gynecol. 1980;138(7):1055-8.

5. Vimala N, Kothari N, Mittal S, Kumar S, Dadhwal V. Primary Ovarian Abscess in Pregnancy. JK Sci. 2004;6(1):40-2.

Cite this article as: Pratapwar DD, Bhure NM, Zunjare SP. A case report: ruptured primary ovarian abscess in pregnancy. Int $\mathrm{J}$ Reprod Contracept Obstet Gynecol 2021;10:3627-9. 